\title{
ANÁLISE DAS PRÁTICAS DE GESTÃO AMBIENTAL DIVULGADAS PELO VAREJO SUPERMERCADISTA
}

\section{ANALYSIS OF ENVIRONMENTAL MANAGEMENT PRACTICES DISCLOSED BY RETAIL SUPERMARKET}

\author{
Alain Jacques Camille Winandy ${ }^{1}$; Amarilis Lucia Casteli Figueiredo Gallardo ${ }^{2}$ \\ ${ }^{1}$ Associação Brasileira de Supermercados - ABRAS - São Paulo - Brasil \\ alainwinandy@gmail.com \\ ${ }^{2}$ Universidade de São Paulo e Universidade Nove de Julho - São Paulo - Brasil \\ amarilislcfgallardo@gmail.com
}

\begin{abstract}
Resumo
O setor de varejo supermercadista é o líder de venda de produtos de consumo no país e um dos principais segmentos da economia. Ao ciclo de comercialização dessa importante cadeia de suprimentos associam-se impactos ambientais relacionados ao esgotamento dos recursos naturais e à geração de resíduos. As principais redes de supermercados vêm realizando ações voltadas ao meio ambiente no varejo. Com vistas a contribuir para efetiva inserção da dimensão ambiental nas operações do supermercado convencional brasileiro, este artigo tem como objetivo discutir as práticas de gestão ambiental do varejo supermercadista divulgadas por seis grandes redes de supermercados: três internacionais e três nacionais. As práticas de gestão ambiental dessas empresas foram analisadas de acordo com a sequência estabelecida na norma NBR ISO 14001/94. Os resultados da pesquisa mostram que os aspectos ambientais das seções de venda do supermercado convencional, identificados com base em dados primários, estão contemplados no contexto das práticas de gestão ambiental adotadas pelas empresas estudadas. Quanto aos elementos do sistema de gestão ambiental, apenas as etapas de política ambiental e planejamento têm seus dados divulgados de modo mais abrangente nos sítios oficiais de comunicação dessas redes. A ausência de divulgação dos dados das etapas de implantação e verificação não permite avaliar a eficácia do gerenciamento ambiental sobre os aspectos ambientais do setor.
\end{abstract}

Palavras-chave: varejo supermercadista; supermercado; sistema de gestão ambiental; impacto ambiental.

\section{Introdução}

O setor de varejo supermercadista é o líder de venda de produtos de largo consumo no país e um dos principais segmentos da economia nacional, com participação, segundo a Associação Brasileira de Supermercados (2014), de 5,6\% no PIB brasileiro. O varejo supermercadista representa mais de $40 \%$ do setor de comércio, conforme classificação do Instituto Brasileiro de Geografia e Estatística (2012). 
Dentro do varejo supermercadista, o formato supermercado, que inclui hipermercado, responde pelo faturamento de $64 \%$ do setor. O setor supermercadista no Brasil conta com mais de oitenta e quatro mil lojas, quase um milhão de empregados, 21,1 milhões de $\mathrm{m}^{2}$ de área de vendas, 210,6 mil check-outs e faturamento de 272,2 bilhões de reais em 2013 (ASSOCIAÇÃO BRASILEIRA DE SUPERMERCADOS, 2014).

As operações associadas à seção de vendas dos supermercados são responsáveis por uma série de impactos ambientais significativos (SUAMIR; TASSOU; MARRIOT, 2012). Conforme Demajorovic (2006), enquanto o setor industrial crescentemente se vê obrigado a incorporar em suas estratégias ações que visem internalizar parte dos seus custos ambientais, o setor de serviços ainda permanece à margem nesse debate. Em estudo mais recente, Delai e Takahashi (2013) também corroboram a tímida discussão da sustentabilidade no varejo destacando, entretanto, o papel chave do setor nesse contexto dado seu posiconamento privilegiado entre oferta e demanda.

Segundo Styles, Schoenberger e Galvez-Matos (2012), os varejistas posicionam-se em situação estratégica para alavancar a melhoria do ambiente na própria cadeia e na cadeia de fornecimento de produtos pela relação que desempenha entre fornecedores e consumidores, sendo relevante conhecer as práticas ambientais adotadas pelo setor. Entretanto, Araujo e Carvalho (2011), ponderam que "a complexa relação entre o meio ambiente e a cadeia varejista requer boas técnicas administrativas e habilidade organizacional para que as empresas alcancem a aprendizagem necessária para transformar suas estratégias ambientais em vantagens competitivas e financeiras."

Com vistas a contribuir para o debate da efetiva inserção da dimensão ambiental no setor de operações do varejo supermercadista brasileiro, entende-se como relevante desenvolver pesquisa que examine como as práticas de gestão ambiental são oficialmente divulgadas por essas empresas, estabelecendo como questão de pesquisa: Como as práticas de gestão ambiental divulgadas por grandes redes de supermercado estão alinhadas aos principais aspectos ambientais das suas atividades e às boas práticas esperadas pelo setor?

Entende-se que essa perspectiva de análise pode representar como essas empresas querem ser reconhecidas quanto à inserção ambiental na sua cadeia de operações e o quanto isso está alinhado à expectativa das boas práticas disseminadas para esse setor de serviços enquanto implementação de gestão ambiental.

Desse modo, este artigo tem como objetivo principal discutir o sistema de gestão ambiental nas operações do varejo supermercadista a partir das práticas divulgadas por grandes redes de supermercados internacionais e nacionais. São objetivos específicos desse artigo: verificar o alinhamento entre as práticas de gestão ambiental divulgadas pelas redes de supermercado e o gerenciamento dos aspectos e impactos ambientais identificados no processo de comercialização final dos produtos nesses supermercados; e analisar os principais elementos do sistema de gestão 
ambiental adotados pelas empresas quanto às boas práticas em gestão ambiental no setor de serviços, em especial do varejo.

\section{Sistema de Gestão Ambiental Empresarial no Setor de Varejo Supermercadista}

O Sistema de Gestão Ambiental (SGA) associado ao sistema de gestão empresarial compõem a estratégia de Responsabilidade Social Corporativa (RSC) de uma organização. De acordo com Amadeu Junior, Gelman e Macedo (2008), RSC é uma forma de gestão em que a organização engloba, além das ações para reduzir os impactos socioambientais ou atender a sociedade, valores éticos e transparentes com aqueles que se relaciona direta ou indiretamente. Hamza e Dalmarco (2013) verificaram que o setor supermercadista brasileiro demonstra alguma integração entre práticas de RSC e de sustentabilidade.

Barros et al (2010) destacam que a promoção de sustentabilidade empresarial consiste em desafio para as organizações de pequeno porte, dada a dependência dessa estratégia para sua competitividade, da sua relação com o meio ambiente, bem como de ações de responsabilidade social.

Conforme a Federação das Indústrias do Estado de São Paulo (2007), o SGA tem potencial para aumentar a competitividade das empresas. Motta e Rossi (2001) recomendam investimento empresarial em gestão ambiental de modo a constituir vantagem competitiva. Soares e Pimenta (2011) salientam que a adoção de um SGA integrado ao conjunto de atividades de gestão auxilia a adequação das normas de gerenciamento ambiental e permite às organizações manterem posições comerciais conquistadas.

Llach et al (2013), assim como Demajorovic (2006), ressaltam a pouca atenção dedicada ao desenvolvimento de estudos sobre as práticas ambientais no setor de serviços em geral e destacam que há evidências entre adoção de práticas ambientais e melhoria de desempenho financeiro e competitividade.

Em estudo recente Ferenhof et al (2014) realizaram um estudo bibliométrico sobre sistemas de gestão ambiental em pequenas e médias empresas e concluíram que os principais aspectos dos sistemas de gestão ambiental incorporadas nessas empresas referem-se a: certificação, análise de falhas e melhoria de implementação, responsabilidade ambiental e mitigação dos impactos ambientais. Ademais os autores conseguiram ressaltar que a ênfase da pesquisa com gestão ambiental e empresas de pequeno e médio porte estão relacionados a: falta de conhecimento sobre os impactos ambientais; necessidade de treinamento, política, consultoria, cooperação empresarial e integração de sistemas; custos elevados no início da implementação e ganhos morais e redução de custos emparelhado com a sustentabilidade a médio prazo, bem como melhoria da imagem e da aquisição de novos clientes, também aludidas a possibilidade de adquirir vantagens competitivas. 
Os efeitos da pressão gerada pelos stakeholders (partes interessadas), bem como a complexidade da sua relação com as organizações nas questões ambientais, foram estudados por González-Benito, Lannelongue e Queiruga (2011), de modo a demonstrar a dependência do desenho do sistema de gestão ambiental adotado pela força exercida pelos stakeholders nesse contexto.

Conforme Epelbaum (2006) em uma organização, o SGA representa parte do sistema de gestão que desenvolve e implementa uma política ambiental, além de gerenciar aspectos ambientais, distinguindo da prática usualmente empregada em gestão ambiental, por considerá-la integrada à gestão empresarial. Segundo Walker (2008) as organizações estão cientes que possuir um SGA, nos moldes da ISO 14001, cria benefícios e economias tangíveis.

De acordo com Barbieri (2004), a empresa pode criar seu próprio modelo de SGA ou utilizar modelos genéricos. Dentre os modelos de SGA adotados mundialmente destacam-se, principalmente, os da EMAS e os da série ISO 14001. Morrow e Rondinelli (2002) afirmam que a ISO 14001 tem se tornado o modelo padronizado de uso preponderante nas empresas, internacionalmente, estando a EMAS restrita a algumas empresas na Europa. Para com Gallez e Moroncini (2003), as principais diferenças entre os dois sistemas normativos referem-se à análise ambiental preliminar e declaração ambiental presentes apenas na EMAS.

A série ISO 14000/2004 e sua equivalente brasileira ABNT NBR ISO 14001 (ASSOCIAÇÃO BRASILEIRA DE NORMAS TÉCNICAS, 2004) tratam de sistema de gestão ambiental e suas fases correspondem a: a) definição da política ambiental; b) planejamento, que engloba aspectos ambientais, exigências legais, objetivos e metas ambientais e programa(s) ambiental(is); c) implantação, que consiste de definir e operacionalizar a estrutura e responsabilidades, a formação, sensibilização e competência, a comunicação, documentação, controle operacional e prevenção de situação de emergências; d) verificação e correção, que compreendem a vigilância e mensuração, ações corretivas, auditoria e revisão da direção.

Em termos de gestão ambiental e varejo, Braga Junior (2007) afirma que as questões ambientais têm ganhado espaço no varejo estão relacionadas a temas como gestão de resíduos, cadeia de produtos e design de embalagens. Apenas recentemente algumas iniciativas vêm sendo estabelecidas para internalização da variável ambiental no setor varejista, a maioria desenvolvida para varejo em geral, não especificamente para o segmento supermercadista.

A Associação Paulista de Supermercados (APAS) produziu o guia prático Apas Supermercado Sustentável no qual são recomendados oito passos para a promoção da sustentabilidade no setor, dentre os quais há um específico em que se preconiza a avaliação dos impactos sociais e ambientais de sua operação (ASSOCIAÇÃO PAULISTA DE SUPERMERCADOS, 2008). A APAS também lançou o guia da loja verde (ASSOCIAÇÃO 
PAULISTA DE SUPERMERCADOS, 2011), com orientações dentre outras voltadas às operações das seções sobre consumo de água e energia, gestão de resíduos e uso de sacolas.

Há outras iniciativas relevantes para o tratamento das questões de meio ambiente no varejo, como as propostas pela FGV/EAESP e CEV (Centro de excelência em varejo), o site Varejo Sustentável (2012); e o guia prático FGV - GVcev de responsabilidade social e sustentabilidade no varejo e iniciativas como o trabalho "indicadores de responsabilidade social nas empresas varejistas" (FUNDAÇÃO GETÚLIO VARGAS, 2005), realizado em conjunto com o Instituto Ethos.

De acordo com Araujo e Carvalho (2011), a formação de estratégias ambientais, dentro da adoção de sistemas de gestão ambiental no segmento do varejo, é um grande desafio que requer a realização de mudanças organizacionais que permitam capacitar a implementação bem sucedidas de estratégias ambientais. Para Raful, Juchem e Cavalheiro (2010), a adoção de práticas de gestão ambiental pode constituir, dentre uma série de outros benefícios, um diferencial competitivo para as empresas.

No Fórum do Varejo e Consumo sustentável, realizado em 2009, Parente et al (2009) destacaram como três áreas propícias ao desenvolvimento do varejo em prol da sustentabilidade: a) o setor de varejo deve incentivar e controlar e gestão de impactos sociais e ambientais na construção e operações de suas lojas; b) os varejistas podem incentivar seus fornecedores a desenvolver produtos diferenciados do ponto de vista social e ambiental; e c) os varejistas podem incentivar os consumidores a comprar produtos sustentáveis, bem como servir de agente ativo no uso e descarte de produtos, por meio de ações de educação ambiental.

A pesquisa sobre a temática ambiental aplicada ao varejo encontra-se em emergência. Thompson (2007) relaciona mudanças para o varejo reduzir a pegada de carbono e energia e ao mesmo tempo diminuir custos e apropriação de recursos naturais em suas operações. Erol et al (2009) propuseram uma série de indicadores para a avaliação de desempenho de sustentabilidade no varejo supermercadista. Feres (2009), em pesquisa sobre o mesmo tema no Brasil, enfatiza a utilização de indicadores de desempenho ambiental, em conjunto com estratégia relacionada ao controle dos aspectos e impactos ambientais, para uma atuação do setor mais eficaz em relação ao meio ambiente. A dimensão social da sustentabilidade nas práticas de pequenos e médios supermercados brasileiros foi objetivo da pesquisa de Marques, Mendonça e Jabbour (2010). Por outro lado, Wiese et al (2012) verificaram na pesquisa sobre varejo um atraso de mais de dez anos na discussão dos temas sustentabilidade e meio ambiente em comparação à indústria e a outros campos da pesquisa no próprio varejo. 


\section{Método da Pesquisa}

Este estudo é de natureza exploratória e de caráter qualitativo. Como estratégia de pesquisa para consecução dos objetivos optou-se por estudos de casos múltiplos, com fonte de evidências a partir de observações diretas e documentação. Essa opção metodológica respalda-se em discussões estabelecidas por Yin (2005), visto o objetivo da pesquisa em alcançar generalizações amplas baseadas nas fontes evidências definidas, de modo a permitir extrapolações sobre um fenômeno contemporâneo - a implantação de sistema de gestão ambiental em supermercados.

Os procedimentos metodológicos empregados consistiram de:

a) revisão bibliográfica sobre sistema de gestão ambiental empresarial no varejo supermercadista;

b) obtenção de dados primários: observações diretas em supermercados nacionais para levantamento das operações de comercialização de varejo e identificação de aspectos e impactos ambientais resultantes;

c) estudo documental: compilação e análise de dados obtidos nos sítios oficiais das empresas objeto da pesquisa acerca das práticas de gestão ambiental das empresas selecionadas;

d) tratamento e análise integrada dos dados primários e secundários dessa pesquisa.

\subsection{Seleção das redes de varejo supermercadista}

Como esse estudo tem natureza prospectiva, na primeira etapa foi realizada uma pesquisa exploratória visando identificar empresas supermercadistas no mundo e no Brasil, reconhecidamente destacadas em RSC, com política ambiental definida e procedimentos de gestão ambiental implantados. Para essa seleção, priorizou-se então o reconhecimento das unidades de varejo por organismos ou associações que tratam exclusivamente de temas relacionados ao varejo.

A organização Consumers International, fundada no Reino Unido, em 1960, representa mais de 220 grupos em 115 países, publicou, em 2010, um relatório (CONSUMERS INTERNATIONAL, 2010) que avalia o envolvimento das empresas europeias em matéria de RSC e a empresa Coop Italia estava classificada em primeiro lugar. Michael Porter, considerado referência nos temas de estratégia competitiva e aplicação de princípios em RSC, em entrevista a Herzog (2008), destaca a rede varejista americana Whole Foods Market (WFM). Em consulta formal ao Instituto Ethos (2010) de empresas e responsabilidade social, foram indicadas no Brasil as empresas Wal-Mart, Grupo Pão de Açúcar (GPA) e Carrefour destacadas como "exemplos de supermercados que atuam de forma socialmente responsável e que têm diversas ações em relação ao tema."i. Assim, as três redes brasileiras de maior faturamento, embora duas com matriz internacional, foram agregadas às outras duas empresas internacionais que não possuem filiais no Brasil. 
De modo a equilibrar o universo de análise entre redes nacionais e internacionais, a Tesco, do Reino Unido, foi adicionada à pesquisa, totalizando seis casos. Sua inclusão justifica-se pela ação destacada e reconhecidamente inovadora (REINARTZ et al, 2011) em RSC e pelo foco do negócio em pegada de carbono. Essa amostra é considerada representativa para a consecução do objetivo geral da pesquisa e seu desenvolvimento em abordagem qualitativa.

A partir de informações divulgadas nos sítios oficiais dessas empresas do setor varejista (WHOLE FOODS MARKET, 2010; 2011; COOP AMBIENTE, 2012; COOP ITALIA, 2010, 2012; E-COOP, 2012; TESCO, 2010, 2011, 2012; GRUPO PÃO DE AÇÚCAR, 2012a, 2012b; 2012c; WALMART BRASIL, 2008，2010，2011; WALMART CORPORATIVO, 2011; WALMART INTERNACIONAL，2011; WALMART SUSTENTABILIDADE，2011; CARREFOUR 2010, 2011a, 2011b, 2011c, 2011d; 2012) apresentam-se alguns dados gerais sobre as mesmas, consolidados no Quadro 1.

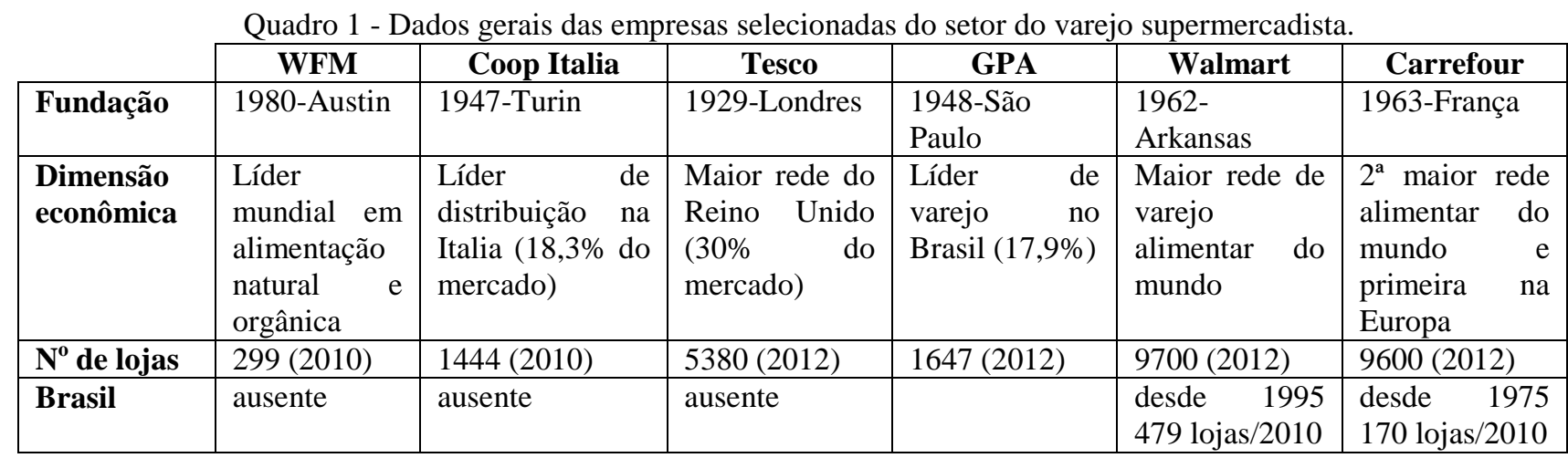

Fonte: produzido pelos autores com dados obtidos nos sites oficiais das empresas (Whole Foods Market, 2010; 2011; Coop Ambiente, 2012; Coop Italia, 2010, 2012; E-Coop, 2012; Tesco, 2010, 2011, 2012; Grupo Pão de Açúcar, 2012a, 2012b; 2012c; Walmart Brasil, 2008, 2010, 2011; Walmart Corporativo, 2011; Walmart Internacional, 2011; Walmart Sustentabilidade, 2011; Carrefour 2010, 2011a, 2011b, 2011c, 2011d; 2012).

Dessa consulta às informações divulgadas pelas empresas: o WFM é uma das empresas com maior crescimento e lucratividade no mercado norte americano, desde o início de suas operações teve atuação relacionada à saúde e meio ambiente; a Coop Itália é líder no varejo supermercadista italiano e atua com cooperativas locais; a Tesco é líder do setor no Reino Unido e vem recentemente incorporando valores ambientais às suas operações; o Walmart no Brasil vem procedendo a incorporação de valores ambientais nas suas operações; o Carrefour no Brasil também apresenta práticas de gestão social e ambiental aos seus negócios; e o GPA, o maior varejista brasileiro, mesmo não possuindo ainda um SGA formalizado, relata investimentos em diversas ações ambientais.

\subsection{Análise dos dados das redes de varejo supermercadista}

A segunda etapa da pesquisa compreendeu a caracterização do objeto da pesquisa, operações de comercialização do varejo supermercadista, e identificação de aspectos e impactos ambientais 
associados; e a análise dos sistemas de gestão ambiental das seis empresas supermercadistas selecionadas para pesquisa quanto aos elementos do sistema de gestão ambiental pelas fases da norma NBR ISO 14.001.

Para o desenvolvimento dessa pesquisa, adotou-se como unidade de análise o supermercado convencional. Esse formato de loja caracteriza-se por área de vendas de oitocentos a dois mil e quinhentos metros quadrados, número médio de doze mil itens, em média cinco por cento de participação de não alimentos, de oito a dezesseis check-outs (ASSOCIAÇÃO BRASILEIRA DE SUPERMERCADOS, 2010, p. 41) contendo seções de mercearia, hortifruti, carnes, aves, frios, laticínios, peixaria e bazar (PARENTE, 2007, p. 30).

Para a obtenção dos dados primários das operações dos supermercados selecionados nesta pesquisa foram realizadas visitas periódicas às três redes de supermercados brasileiras da amostra desta pesquisa no período de 2011 e 2012. Essas visitas permitiram: identificar as principais seções de venda de supermercado convencional; caracterizar as principais operações de comercialização; e verificar as interações diretas entre essas operações e o meio ambiente. Essas visitas abrangeram as etapas de recebimento e destinação dos materiais em todas as seções de vendas consideradas nesta pesquisa. As redes internacionais não foram objeto de visita durante essa pesquisa. Entretanto, o material divulgado por essas empresas do exterior permitiram assumir a similaridade entre as redes nacionais e internacionais quanto às atividades do setor de comercialização de mercadorias.

Para aquisição dos dados referentes às práticas de gestão ambiental das empresas selecionadas para a pesquisa, foram consultados documentos nos sítios das empresas, no período de agosto de 2010 a novembro de 2012, como relatórios anuais de sustentabilidade e demais dados relativos a práticas de gestão ambiental divulgados por essas organizações.

As variáveis constitutivas da análise referem-se às principais etapas do Sistema de Gestão Ambiental, em consonância a lacunas de pesquisa aplicada identificadas por Oliveira e Machado (2010) e Delai e Takahashi (2013) quanto à organização e integração de práticas ambientais no setor do varejo supermercadista. Realizou-se análise integrada das ações relacionadas ao gerenciamento dos aspectos ambientais nos supermercados visitados e das práticas de gestão ambiental nas empresas selecionadas, de modo a identificar um arcabouço mínimo representativo de boas práticas em gestão ambiental.

Cabe destacar algumas limitações da pesquisa. As práticas de gestão ambiental foram obtidas exclusivamente a partir da coleta de informações secundárias utilizadas por meio de fontes oficiais. Embora esforços efetivos tenham sido envidados para a realização de entrevistas com as unidades brasileiras e do exterior, os poucos retornos obtidos não se revelaram cientificamente consistentes e não puderam ser triangulados com os dados documentais e levantamentos primários para serem inseridos nesta análise. Assim foi realizada uma interpretação livre do conteúdo dessas 
fontes apenas com o subsídio do referencial bibliográfico, refletindo a opinião técnico-científica dos autores acerca das práticas ambientais divulgadas por essas redes no período de referência de coleta dos dados. Diferente da pesquisa realizada por Cruz, Pedrozo e Martinet (2007) que compararam a estratégia de desenvolvimento sustentável de duas grandes empresas do setor de varejo internacional e apresentaram uma matriz de análise para suas filiais no Brasil, essa pesquisa não almejou esse objetivo. Embora duas das unidades nacionais de análise tenham origem internacional, o aspecto da influência das práticas ambientais da matriz nas unidades nacionais não foi escopo desta pesquisa. Assume-se nessa pesquisa que, como essas duas redes estão atuando no país há muito tempo e com número expressivo de unidades de venda, as práticas nacionais devem se sobrepor a eventuais orientações da matriz, reforçada pelas características do setor de venda de produtos no varejo.

\section{Resultados}

São apresentados os principais aspectos e impactos ambientais para supermercados, de acordo com o processo de comercialização e as seções de venda e as práticas de gestão ambiental, organizadas nas etapas principais do Sistema de Gestão Ambiental (SGA) para as redes de supermercado analisadas.

\subsection{Aspectos e impactos ambientais em supermercados convencionais}

A operação dos supermercados é principalmente uma transação de compra e revenda de mercadorias com foco no consumidor final. Os supermercados recebem mercadorias de fornecedores e as expõem nas áreas de vendas para comercializá-las ao consumidor final. Os itens comercializados são industrializados, processados (por exemplo, o fatiamento de queijo para venda do produto fracionado, ou o corte e limpeza da carne bovina), ou servem de insumo para fabricação no ponto de venda (por exemplo, a farinha comprada a granel para fabricação de pão).

O supermercadista pode recepcionar as mercadorias diretamente na loja ou em um depósito central, em que será realizada a distribuição para diversas lojas. Na loja, a depender do tipo de produto (congelado, resfriado ou seco), a mercadoria recebida pode ser destinada diretamente à área de vendas ou estocada em depósito interno, câmara resfriada ou congelada, para posteriormente ser encaminhada à área de vendas, de processamento ou fabricação. O processo típico de comercialização em um supermercado convencional, caracterizado com base nas visitas aos supermercados nacionais objetos desta pesquisa, no período entre 2010 e 2012, está representado na Figura 1. 
Figura 1 - Representação esquemática do fluxo de comercialização em um supermercado convencional.

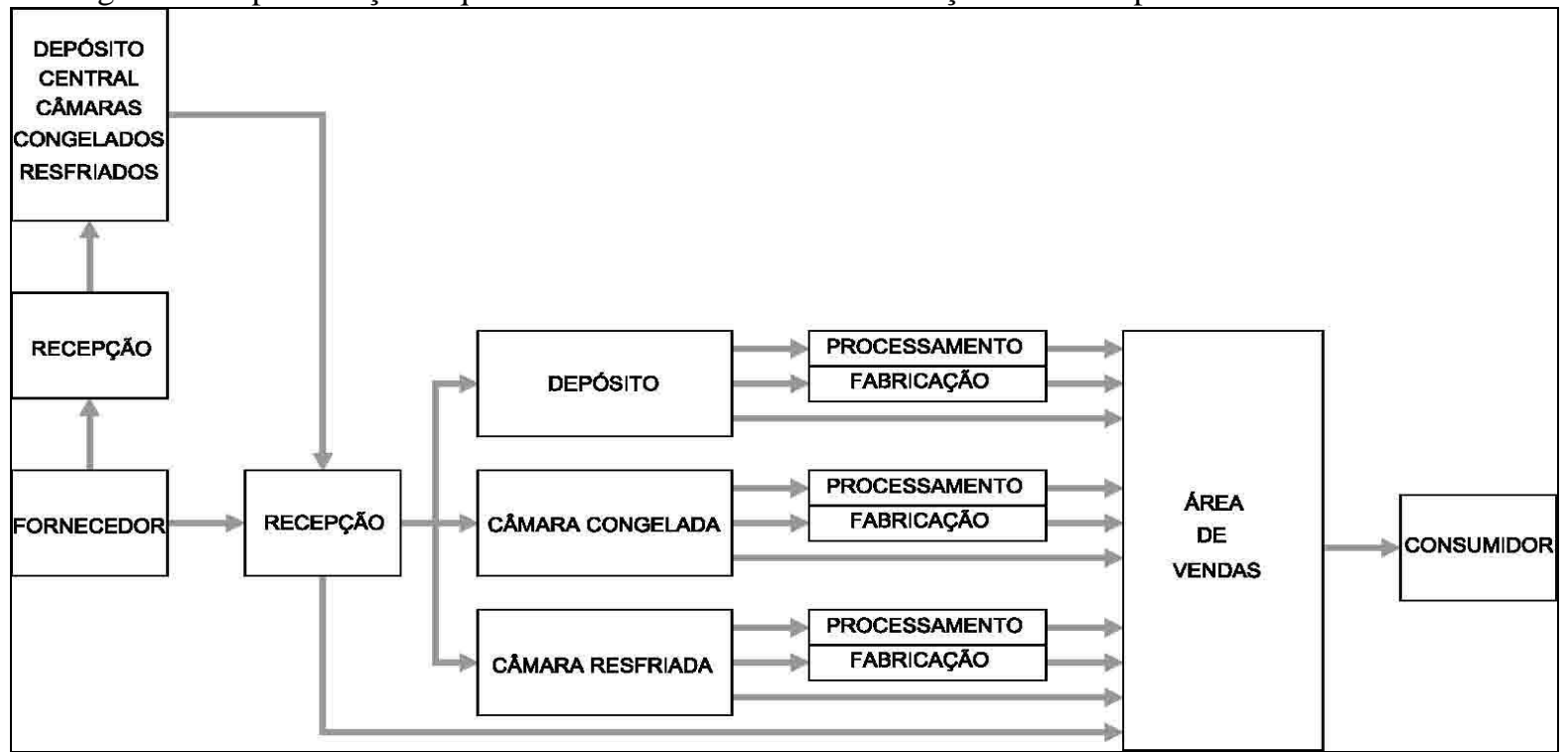

Fonte: Pesquisa de campo $(2011,2012)$.

A área de vendas de um supermercado é subdividida em seções. A lógica, em geral, prevê o agrupamento de produtos com características similares, considerando-se as necessidades de preparação, armazenamento, exposição e atendimento.

As peculiaridades dos processos de comercialização e os equipamentos necessários para a operação no tocante à geração de resíduos e efluentes e necessidades de insumos orientaram o agrupamento de atividades ou setores. Assim, às 15 atividades principais das seções do supermercado convencional foram associados os aspectos ambientais do supermercado convencional, conforme apresentado no Quadro 2.

Quadro 2 - Síntese dos principais aspectos ambientais associados à operação das diversas seções de um supermercado convencional.

\begin{tabular}{|c|c|c|c|c|c|c|c|c|c|c|c|c|c|c|c|c|}
\hline & \multicolumn{15}{|c|}{ Principais secões de um supermercado convencional } \\
\hline & & a) & b) & c) & d) & e) & f) & g) & h) & i) & j) & k) & l) & m) & n) & o) \\
\hline \multirow{20}{*}{ 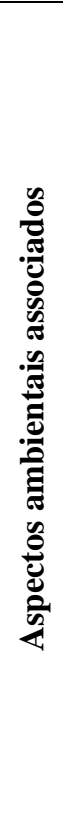 } & 1 & & & & & & & & & & & & & & & \\
\hline & 2 & & & & & & & & & & & & & & & \\
\hline & 3 & & & & & & & & & & & & & & & \\
\hline & 4 & & & & & & & & & & & & & & & \\
\hline & 5 & & & & & & & & & & & & & & & \\
\hline & 6 & & & & & & & & & & & & & & & \\
\hline & 7 & & & & & & & & & & & & & & & \\
\hline & 8 & & & & & & & & & & & & & & & \\
\hline & 9 & & & & & & & & & & & & & & & \\
\hline & 10 & & & & & & & & & & & & & & & \\
\hline & 11 & & & & & & & & & & & & & & & \\
\hline & 12 & & & & & & & & & & & & & & & \\
\hline & 13 & & & & & & & & & & & & & & & \\
\hline & 14 & & & & & & & & & & & & & & & \\
\hline & 15 & & & & & & & & & & & & & & & \\
\hline & 16 & & & & & & & & & & & & & & & \\
\hline & 17 & & & & & & & & & & & & & & & \\
\hline & 18 & & & & & & & & & & & & & & & \\
\hline & 19 & & & & & & & & & & & & & & & \\
\hline & 20 & & & & & & & & & & & & & & & \\
\hline
\end{tabular}




\section{1}

Fonte: Autoria própria.

Legenda das seções de um supermercado convencional: a) recepção de mercadorias; b)depósito de mercearia e bazar; c) câmara de congelados; d) câmara de resfriados; e) mercearia; f) hortifruti; g) carnes; h) aves; i) frios; j) laticínios; k) peixaria; 1) bazar; m) equipamentos e máquinas; n) administração e frente de caixa; o) produtos e logística. Legenda dos aspectos ambientais: Geração de resíduos: 1) plásticos, 2) papelão, 3) papel, 4) madeira, 5) isopor, 6) filme PVC, 7) produtos, 8) subprodutos sólidos; 9) subprodutos líquidos; Coleta de resíduos: 10) coleta seletiva; Consumo de energia: 11) eletricidade, 12) gás, 13) combustíveis; Consumo de: 14) água, 15) água potável, 16) papel; 17) produtos químicos de limpeza; 18) produtos de manutenção; 19) preocupação de aspectos de produtos comercializados; 20) redução de emissão de $\mathrm{CO} 2$; 21) troca de fluidos refrigerantes.

Com os subsídios técnicos de Sánchez (2014) e Barbieri (2004), foram identificados para os aspectos ambientais relacionados às 15 seções de venda, os principais impactos ambientais associados à operação de um supermercado convencional, conforme apresentado no Quadro 3.

Quadro 3 - Impactos ambientais de um supermercado convencional associados aos aspectos ambientais.

\begin{tabular}{|l|l|}
\hline \multicolumn{1}{|c|}{ Aspectos ambientais } & \multicolumn{1}{|c|}{ Impactos ambientais } \\
\hline $\begin{array}{l}\text { Geração de resíduos: } \\
\text { (1) plásticos, (2) papelão, (3) papel, (4) madeira, (5) isopor, (6) filme } \\
\text { PVC, (7) produtos, (8) subprodutos sólidos }\end{array}$ & Alteração da qualidade do solo \\
\hline Geração de resíduos: (9) subprodutos líquidos & Alteração da qualidade da água e do solo \\
\hline Coleta de resíduos: (10) coleta seletiva & Alteração da qualidade do solo \\
\hline Consumo de energia: (11) eletricidade & Esgotamento de recursos naturais \\
\hline Consumo de energia: (12) gás, (13) combustíveis & Esgotamento de recursos fósseis \\
\hline $\begin{array}{l}\text { Consumo de: (14) água, (15) água potável, (16) papel - impressoras, } \\
\text { tickets, cupons }\end{array}$ & Esgotamento de recursos naturais \\
\hline (17) produtos químicos de limpeza & Contaminação do solo e da água \\
\hline (18) produtos de manutenção & Alteração da qualidade da água \\
\hline (19) preocupação de aspectos de produtos comercializados & Contaminação do solo e da água \\
\hline (20) redução de emissão de CO2 & $\begin{array}{l}\text { Alteração da qualidade do ar, efeito estufa, } \\
\text { chuva ácida }\end{array}$ \\
\hline (21) troca de fluidos refrigerantes & Depleção da camada de ozônio \\
\hline
\end{tabular}

Fonte: Autoria própria.

Da análise dessas 15 atividades ou setores relacionados à área de comercialização do supermercado convencional, foi possível identificar 21 aspectos ambientais aos quais se associam cinco categorias amplas de impactos ambientais. As categorias mais frequentes referem-se à alteração da qualidade do solo e água, seguidas de esgotamento de recursos naturais e fósseis.

\subsection{Sistema de gestão ambiental dos supermercados}

As quatro etapas principais de SGA, conforme norma ABNT NBR ISO 14001/2004 (ASSOCIAÇÃO BRASILEIRA DE NORMAS TÉCNICAS, 2004), foram analisadas quanto ao formato e conteúdo do SGA de cada empresa selecionada na pesquisa, por meio das informações veiculadas pelas unidades pesquisadas (WHOLE FOODS MARKET, 2010; 2011; COOP AMBIENTE, 2012; COOP ITALIA, 2010, 2012; E-COOP, 2012; TESCO, 2010, 2011, 2012; GRUPO PÃO DE AÇÚCAR, 2012a, 2012b; 2012c; WALMART BRASIL, 2008, 2010, 2011; WALMART CORPORATIVO, 2011; WALMART INTERNACIONAL，2011; WALMART SUSTENTABILIDADE，2011; CARREFOUR 2010, 2011a，2011b，2011c，2011d; 2012). A despeito da importância da etapa de implantação e da etapa de verificação e correção do SGA, as 
informações divulgadas pelas redes analisadas não abordam em detalhe essas etapas, o que não permite estabelecer uma análise pormenorizada. Desse modo, apresentam-se os resultados da análise das etapas de definição de política ambiental e de planejamento do SGA, consideradas suficientes para atingir os objetivos da pesquisa.

Quanto à etapa de implantação pode-se destacar que a estrutura de responsabilidades é bem distinta entre as empresas analisadas, sendo essa uma característica peculiar do SGA de cada supermercado. Pelo estudo documental não foram encontradas descrições acerca do controle (documental e operacional) do SGA das empresas selecionadas. Do mesmo modo, informações sobre prevenção de situações de urgência e capacidade de ação são escassas. Apenas a Coop Itália declara seguir um padrão definido, mas não o apresenta. Quanto às formas de verificação e correção as empresas divulgam que as mais utilizadas são as auditorias internas e externas, subsidiadas pelo monitoramento de indicadores ambientais para acompanhamento da implantação e execução dos processos e da análise da evolução e efetividade das medidas e planos adotados e do sistema de gestão ambiental como um todo. Quanto aos indicadores usados, há uma gama muito diversificada que se associam, preferencialmente, a índices de mercado e às metas ambientais estabelecidas pelas empresas.

\subsubsection{Política ambiental}

Das três empresas internacionais pesquisadas, a Coop Itália possui SGA baseado na norma Emas; a Tesco tem foco na pegada de carbono e o WFM tem uma política ambiental difundida entre seus stakeholders. Das empresas nacionais, o estágio de implantação do SGA é mais incipiente, o Walmart está avançando na construção de suas práticas de gestão; o Carrefour tem realizado ações em prol da implementação efetiva do SGA; e o GPA está desenvolvendo várias ações, mas ainda carece de uma política melhor definida e comunicada.

Das empresas pesquisadas, as internacionais possuem declaração ambiental: WFM, Coop Itália, que a revalida anualmente, e Tesco. As empresas brasileiras, porém, têm sites específicos sobre o tema, onde explicitam sua conduta com relação ao meio ambiente, mas não em um formato de declaração formalizada.

De modo a identificar elementos para análise da política ambiental dos supermercados foram definidas categorias a partir do próprio conteúdo dessas mesmas políticas em associação a aspectos relevantes das atividades de operação dos supermercados, como apresentado no Quadro 4. 
Quadro 4 - Categorias relevantes da política ambiental dos sistemas de gestão ambiental dos supermercados.

\begin{tabular}{|c|c|c|c|c|c|c|}
\hline & WFM & Coop Italia & Tesco & GPA & Walmart & Carrefour \\
\hline Produtos & grande foco & grande foco & foco & baixo foco & foco & baixo foco \\
\hline $\begin{array}{l}\text { resíduos, recur- } \\
\text { sos naturais }\end{array}$ & $\operatorname{sim}$ & $\operatorname{sim}$ & $\operatorname{sim}$ & $\operatorname{sim}$ & $\operatorname{sim}$ & $\operatorname{sim}$ \\
\hline Grande causa & $\begin{array}{l}\text { Clima global e } \\
\text { poluição das } \\
\text { florestas }\end{array}$ & $\begin{array}{l}\text { Mudanças } \\
\text { climáticas e } \\
\text { consumo } \\
\text { sustentável }\end{array}$ & $\begin{array}{l}\text { Mudanças } \\
\text { climáticas }\end{array}$ & $\begin{array}{l}\text { Região } \\
\text { Amazônica }\end{array}$ & $\begin{array}{l}\text { Emissões de } \\
\mathrm{CO}_{2} \text { e recursos } \\
\text { naturais }\end{array}$ & $\begin{array}{l}\text { Mudanças } \\
\text { climáticas }\end{array}$ \\
\hline $\begin{array}{l}\text { Causa } \\
\text { específica }\end{array}$ & $\begin{array}{l}\text { Produção de } \\
\text { óleo de palma }\end{array}$ & $\begin{array}{l}\text { Orgânicos, } \\
\text { pesca susten- } \\
\text { tável, prote- } \\
\text { ção dos } \\
\text { golfinhos, } \\
\text { outros }\end{array}$ & Não observada & $\begin{array}{l}\text { Não } \\
\text { observada }\end{array}$ & $\begin{array}{ll}\text { Compra } & \\
\text { responsável da } \\
\text { cadeia } \\
\text { pescado }\end{array}$ & Não observada \\
\hline $\begin{array}{l}\text { Valores e } \\
\text { stakeholders }\end{array}$ & muito & muito & muito & pouco & médio & pouco \\
\hline
\end{tabular}

Fonte: produzido pelos autores com dados obtidos nos sites oficiais das empresas.

Assim, a partir da análise das políticas ambientais das empresas selecionadas, o conteúdo da política ambiental do SGA dos supermercados analisados pode ser caracterizado nas seguintes categorias:

a) Foco ambiental nos produtos comercializados: como o setor de varejo supermercadista comercializa produtos de diversos fornecedores, seus princípios em relação ao meio ambiente podem entrar em conflito com os impactos ambientais ocasionados por alguns produtos, como por exemplo, produtos de limpeza que podem contaminar o solo. Pela análise da política ambiental, observa-se que algumas empresas são rígidas nesse aspecto. O WFM não comercializa produtos com determinados ingredientes. O Walmart e Coop Itália exigem dos fornecedores melhorias de produtos, inclusive daqueles que já estão nas prateleiras, de modo a torná-los mais amigáveis ambientalmente. A Tesco, por exemplo, tem atuação focada na marca própria, com a promoção de uma linha de produtos ambientalmente adequados. As redes internacionais destacam mais a importância da preocupação ambiental dos produtos que comercializam se comparadas às brasileiras.

b) Energia, resíduos próprios e da cadeia e recursos naturais: todas as empresas incluem a redução de energia em sua política. Além do alinhamento a princípios ambientais, essa postura pode reverter ganhos financeiros tangíveis neste setor tão competitivo. Todas as empresas divulgam que adotam gestão de resíduos, materializada pela política dos 3 Rs (reduzir, reutilizar, reciclar), que pode ser mais abrangente que apenas considerar os resíduos oriundos da própria operação; segundo as informações divulgadas os supermercados vêm, paulatinamente, ampliando a criação de estações de reciclagem para consumidores, por meio do recolhimento de lâmpadas, baterias e outros 
com consequente destinação adequada. Os supermercados divulgam em sua política que reconhecem a escassez crescente dos recursos naturais.

c) Grande causa: manifestação de apoio a grandes causas que extrapolam o alcance da operação direta das redes; aspecto presente em todas as políticas ambientais. Algumas empresas apoiam mais de uma causa. As mudanças climáticas constituem a bandeira principal entre internacionais e nacionais, entretanto, a rede brasileira GPA remete sua política à região Amazônica.

d) Causa específica: geralmente está relacionada diretamente ao varejo e tem menor amplitude que as grandes causas. Essa prática não está tão disseminada, sendo mais frequente nas internacionais. A causa específica pode, eventualmente, orientar um plano de ação mais focado na área ambiental.

e) Compartilhamento de valores e envolvimento dos stakeholders: esses aspectos foram considerados quanto a incentivo a treinamento e promoção de mecanismos para participação de diferentes stakeholders (consumidores, fornecedores, outros) em projetos ambientais patrocinados pelos supermercados investigados. Esses aspectos estão fortemente presentes nas redes internacionais; dentre as nacionais destaque apenas ao Walmart.

\subsubsection{Planejamento}

A apropriada identificação, avaliação e atuação sobre os aspectos ambientais da operação empresa é um componente importante para a implantação do SGA (SEIFFERT, 2008). A identificação desses aspectos permite às empresas do setor supermercadista uma base de referência para atuação sobre suas ações de modo a reduzir a magnitude dos impactos ambientais.

Para discutir a fase de planejamento do SGA foi realizada uma análise de conformidade dos aspectos ambientais identificados (Quadro 3), a partir de dados de levantamentos primários, em relação ao conteúdo expresso na política ambiental, divulgada nos sítios oficiais das empresas objeto dessa pesquisa. O Quadro 5 apresenta essas relações.

Quadro 5 - Aspectos ambientais de supermercados convencionais associados aqueles presentes na etapa de planejamento de SGA das empresas pesquisadas.

\begin{tabular}{|l|c|c|c|c|c|c|}
\hline \multicolumn{1}{|c|}{$\begin{array}{c}\text { Aspectos } \\
\text { ambientais }\end{array}$} & WFM & Coop Italia & Tesco & GPA & Walmart & Carrefour \\
\hline plástico & $\operatorname{sim}$ & $\operatorname{sim}$ & $\operatorname{sim}$ & $\operatorname{sim}$ & $\operatorname{sim}$ & $\operatorname{sim}$ \\
\hline papelão & $\operatorname{sim}$ & $\operatorname{sim}$ & $\operatorname{sim}$ & $\operatorname{sim}$ & $\operatorname{sim}$ & $\operatorname{sim}$ \\
\hline papel & $\operatorname{sim}$ & $\operatorname{sim}$ & $\operatorname{sim}$ & $\operatorname{sim}$ & $\operatorname{sim}$ & sim \\
\hline madeira & só no escopo & $\operatorname{sim}$ & só no escopo & só no escopo & só no escopo & só no escopo \\
\hline isopor & $\operatorname{sim}$ & só no escopo & só no escopo & só no escopo & $\operatorname{sim}$ & sim \\
\hline filme PVC & $\operatorname{sim}$ & só no escopo & só no escopo & só no escopo & $\operatorname{sim}$ & $\operatorname{sim}$ \\
\hline produto & $\operatorname{sim}$ & $\operatorname{sim}$ & $\operatorname{sim}$ & $\operatorname{sim}$ & $\operatorname{sim}$ & $\operatorname{sim}$ \\
\hline
\end{tabular}




\begin{tabular}{|l|c|c|c|c|c|c|}
\hline solido & $\operatorname{sim}$ & só no escopo & $\operatorname{sim}$ & $\operatorname{sim}$ & $\operatorname{sim}$ & só no escopo \\
\hline líquido & só no escopo & só no escopo & $\operatorname{sim}$ & $\operatorname{sim}$ & só no escopo & só no escopo \\
\hline seletiva & $\operatorname{sim}$ & $\operatorname{não}$ & só no escopo & $\operatorname{sim}$ & $\operatorname{sim}$ & sim \\
\hline eletricidade & $\operatorname{sim}$ & $\operatorname{sim}$ & $\operatorname{sim}$ & $\operatorname{sim}$ & $\operatorname{sim}$ & sim \\
\hline gás & só no escopo & $\operatorname{sim}$ & $\operatorname{sim}$ & $\operatorname{sim}$ & $\operatorname{sim}$ & só no escopo \\
\hline combustíveis & $\operatorname{sim}$ & $\operatorname{sim}$ & $\operatorname{sim}$ & $\operatorname{sim}$ & $\operatorname{sim}$ & $\operatorname{sim}$ \\
\hline água & $\operatorname{sim}$ & $\operatorname{sim}$ & $\operatorname{sim}$ & $\operatorname{sim}$ & $\operatorname{sim}$ & sim \\
\hline água potável & não & $\operatorname{sim}$ & não & não & não & só no escopo \\
\hline papel & $\operatorname{sim}$ & $\operatorname{sim}$ & $\operatorname{sim}$ & só no escopo & não & não \\
\hline químicos & $\operatorname{sim}$ & $\operatorname{sim}$ & não & não & não & não \\
\hline manutenção & $\operatorname{sim}$ & não & não & não & não & não \\
\hline comercializados & $\operatorname{sim}$ & $\operatorname{sim}$ & $\operatorname{sim}$ & $*$ & ** & $* * *$ \\
\hline emissão $\mathrm{CO}_{2}$ & $\operatorname{sim}$ & sim & $\operatorname{sim}$ & sim & sim & sim \\
\hline fluidos & não & só no escopo & $\operatorname{sim}$ & sim & sim & sim \\
\hline
\end{tabular}

Fonte: Autoria própria.

Nota: os aspectos ambientais da coluna 1 estão integralmente descritos no Quadro 3.

Legenda: Só no escopo refere-se a não relatado no planejamento do SGA, mas presente no escopo da política ambiental. * - parcialmente, em marca própria e apoio a ações; ** - parcialmente em linha de marca própria; *** - parcialmente, produtos com garantia de origem.

Pelo Quadro 5 constata-se que todas as empresas possuem ações sobre resíduos, consumo de energia, de água e redução de emissão de $\mathrm{CO}_{2}$, principalmente relacionadas à logística (armazenagem, distribuição e transporte). Com relação a resíduos de madeira (pallets, caixas de transporte, embalagens) e gestão sobre conservação de água potável apenas a Coop Itália pratica.

Dos 21 aspectos ambientais descritos no Quadro 3 e aplicados no Quadro 5, excetuando-se preocupação com aspectos dos produtos comercializados, verifica-se um resultado praticamente equilibrado (15 - WFM; 14 - Wal Mart; 13 - Coop Italia, Tesco e GPA e 12 - Carrefour), denotando um conhecimento potencial da grande maioria dos aspectos ambientais associados às atividades da operação. Se considerados que esses aspectos podem não estar relatados, mas estarem presentes no escopo da política, esse percentual se eleva ainda mais (18 - WFM e Coop Italia; 17 Tesco, GPA e Carrefour e 16 - Walmart).

Os programas ambientais das empresas são diversificados e estão alinhados aos objetivos e ações relativas ao meio ambiente dessas organizações. Todas as empresas pesquisadas possuem objetivos e metas ambientais, de acordo com política ambiental e usam indicadores quantitativos, em sua maioria, e também qualitativos. Algumas características particulares desses programas podem ser destacadas:

- o WFM tem como objetivos promover a vitalidade e bem estar dos indivíduos, fornecendo alimentos de alta qualidade; apoiar práticas ambientais; e ser líder em gestão ambiental. Tem como metas quantitativas reduzir o consumo de energia por metro quadrado em todas as lojas em 25\% até 2015, comprar créditos de energia eólica para compensar $100 \%$ da eletricidade utilizada na empresa, e qualitativas, como eliminar o uso de isopor e utilizar painéis solares; 
- a Coop Itália estabelece metas e indicadores relacionados aos produtos, como consumo de papel, toxicidade dos produtos de limpeza (marca própria), consumo de energia e de eficiência energética e coleta seletiva. Monitora indicadores quantitativos e qualitativos de desempenho da logística;

- a Tesco possui metas alinhadas com a grande causa da política ambiental, mudanças climáticas e redução de sua pegada de carbono, assim estabelece redução de $50 \%$ da emissão de $\mathrm{CO}_{2}$ de 2006 até 2020, nas lojas, centros de distribuição e novas lojas, dentre outras metas, a maioria quantitativa;

- no GPA, os indicadores ambientais que compõem o relatório anual e de sustentabilidade 2010 são apenas financeiros e indicam que investimentos em programas e/ou projetos externos representaram, em 2010, mais de 4,8 milhões de reais; não foram encontradas metas específicas nos documentos disponíveis ao público;

- o Walmart destaca metas ambientais para cada um dos seus eixos de atuação: clima e energia, resíduos e produtos; adota metas quantitativas, como reduzir em 50\% o uso de sacolas plásticas até 2013 e implantar a política de compras responsável na cadeia de pescados até 2016; reduzir o consumo de água nas lojas; e outras não quantitativas, como estimular o desenvolvimento de produtos de ciclo fechado;

- no Carrefour, as ações seguem em direção aos seus três compromissos frente ao meio ambiente, mudanças climáticas, preservação da biodiversidade e recursos naturais, redução de desperdício e maximização de reciclagem, com praticamente todas as metas mensuráveis, como por exemplo, cessar a distribuição gratuita de sacolas plásticas descartáveis até 2012.

Os programas ambientais das redes supermercadistas são bastante diferenciados entre si, mas representam ou contemplam a grande maioria dos aspectos ambientais observados em cada cadeia, sem denotar uma capacidade efetiva de gerenciamento integrado desses aspectos visto o formato como são divulgados.

\section{Discussão}

As práticas de gestão ambiental das redes de supermercado, verificadas por meio da sua política ambiental e da implantação dos programas ambientais divulgados nos sítios oficiais de informação, contemplam a grande maioria dos aspectos ambientais identificados nos supermercados objetos da pesquisa. Isso demonstra que há um alinhamento entre os dados divulgados pelas empresas estudadas e observados quanto à adoção e o alcance de sistemas de gestão ambiental no gerenciamento dos impactos ambientais das suas atividades. 
Cotejados os aspectos ambientais dos supermercados investigados, coletados por meio de levantamento primário, aos programas ambientais divulgados por essas empresas, obtidos por meio de informações oficiais, depreende-se que há um elevado conhecimento por parte dessas empresas acerca da grande maioria dos aspectos ambientais e das consequências das suas atividades. Tal constatação permite inferir que as redes investigadas têm potencial efetivo para gerenciar de modo efetivo suas atividades de modo a reduzir os impactos ambientais do setor.

Por outro lado, Delai e Takahashi (2013) pontuam, a partir de pesquisa com oito redes brasileiras do varejo, incluindo as quatro maiores do setor supermercadista, que os varejistas gerenciam suas práticas de sustentabilidade como uma coleção de atividades pontuais e desconectadas ao invés de organiza-las de modo sistemático e integrado por meio de um sistema de gestão. A análise do conteúdo da política ambiental e planejamento do SGA dos seis supermercados investigados nesta pesquisa permite ratificar essas conclusões. Embora os programas ambientais abranjam os aspectos ambientais observados na coleta de dados primários, não se verifica pela análise documental integração efetiva entre esses programas, também corroborada pela carência da divulgação das etapas de implantação e de verificação e correção do SGA, o que pode denotar que não há efetividade ou atuação incisiva no gerenciamento ambiental sobre os principais aspectos ambientais relacionados às atividades de comercialização pelo setor.

Quanto à análise dos principais elementos do sistema de gestão ambiental adotados pelas empresas em relação às boas práticas em gestão ambiental no setor de serviços, em especial do varejo, algumas considerações podem ser realizadas.

Segundo Campos (2012), em pesquisa com pequenas e grandes companhias, a política ambiental foi considerada de modo unânime como o elemento mais importante da ISO 14.001 para o desenvolvimento de SGA. Na política ambiental são definidas as prioridades da empresa em relação ao meio ambiente que servirão de guia para a definição de objetivos, metas e programas ambientais. Da amostra de supermercados analisada observa-se a relevância dessa etapa do SGA, embora as redes internacionais demonstrem ter atingido uma maior complexidade no desenho e nas dimensões de alcance dessas políticas se comparadas às brasileiras. Uma vez que, por exemplo, à exceção da Coop Italia que tem seu SGA baseado na EMAS que obriga a divulgação de uma declaração internacional, as outras internacionais também o fazem em caráter voluntário, embora as brasileiras também reconheçam essa importância e divulguem essas informações ainda de maneira não padronizada.

Pela análise dessas políticas ambientais, observa-se o compartilhamento dos valores e o envolvimento dos stakeholders ainda pouco explorado pelas redes de supermercado nacionais. Empresas como Whole Foods Market, Coop Itália e, mais recentemente, Tesco, envolvem os stakeholders em suas ações, e não por acaso, as duas primeiras empresas se destacam na abordagem 
da temática ambiental e a última vem evoluindo rapidamente no tratamento dessa matéria em seu negócio. A importância do envolvimento dos stakeholders para a efetividade da implantação do sistema de gestão ambiental já havia sido ressaltada na pesquisa desenvolvida por González-Benito, Lannelongue e Queiruga (2011). A missão e a visão de como o supermercado quer operar no futuro e como quer ser percebido pelos seus stakeholders devem estar presentes na definição da política ambiental.

Ao analisar alguns elementos de gestão ambiental de empresas do setor supermercadista, Oliveira e Machado (2010, p. 34), concluíram pela presença da “[...] temática ambiental incorporada a uma abordagem estratégica em nível corporativo [...]”. Esta pesquisa corrobora esses achados, demonstrado pelo conteúdo da política ambiental e os dados do planejamento do SGA divulgados pelas redes de supermercado selecionadas o que denota também a preocupação do varejo em incorporar o tema ambiental nos seus negócios, como caracterizado por Thompson (2007), Braga Junior (2007), Erol et al (2009) e Wiese et al (2012).

A restrita divulgação dos dados de implantação e verificação e correção do SGA, elementos pouco apresentados nos sítios de informação oficiais das empresas pesquisadas, corroboram o estudo realizado por Ferenhof et al (2014). Esses autores enfatizaram a partir de levantamento amplo de pesquisas recentes sobre o tema, que essas etapas do SGA consistem em aspectos relevantes a considerar para a discussão das boas práticas de SGA. Considera-se que a divulgação desses dados permitiria evidenciar eventuais dificuldades encontradas na manutenção do SGA e oportunidades de melhoria do sistema, o que refletiria em aprendizado para outras empresas e transparência para os stakeholders.

\section{Considerações Finais}

A análise realizada com as empresas do setor varejista supermercadista permite concluir que as líderes internacionais e nacionais estão internalizando a variável ambiental nas suas práticas de gestão, de modo a contribuir para tornar seu negócio mais sustentável.

A análise das práticas adotadas pelas seis redes de supermercado selecionadas nesta pesquisa demonstra que há um referencial representativo de boas práticas de gestão ambiental, que pode inclusive constituir-se em benchmarking para o setor, incentivando a adoção de sistema de gestão ambiental por outros supermercados convencionais.

Entretanto, quanto à análise dos elementos do sistema de gestão ambiental, apenas as etapas de política ambiental e planejamento têm seus dados divulgados de modo mais abrangente nos sítios oficiais dessas redes de supermercado. A ausência de dados da etapa de implantação e verificação não permite avaliar a eficácia do gerenciamento ambiental sobre os aspectos ambientais do setor. 
Pela pesquisa realizada pode-se considerar que a adoção mais generalizada de práticas de gestão ambiental, organizadas ou não em SGA, em supermercados de porte inferior aos estudados poderia representar redução da magnitude dos impactos ambientais neste tipo de organização, visto que enseja abordagem sistêmica da variável ambiental nas atividades do setor.

Essa pesquisa concentrou-se especificamente em analisar o sistema de gestão ambiental das grandes redes de varejo supermercadista sob a ótica da divulgação institucional, o que permitiu revelar quais os aspectos ambientais que a empresa engloba em seus programas ambientais, sem entretanto verificar como são efetivamente gerenciados, dado o recorte adotado pela pesquisa. Assim, recomenda-se que pesquisas decorrentes possam investigar, utilizando ferramentas complementares de pesquisa como entrevistas e acesso a documentos internos do SGA, a eficácia da gestão ambiental dessas empresas sobre seus aspectos ambientais.

Essa pesquisa concentrou seu foco na implantação do SGA relacionado aos aspectos da seção de vendas de um supermercado convencional. Acredita-se que outras pesquisas poderiam ser desenvolvidas ampliando esse escopo para áreas que extrapolem as vendas, como as relacionadas aos fornecedores e aos consumidores, denotando de fato aspectos de responsabilidade socioambiental dessa cadeia de serviços. Outras pesquisas a desenvolver referem-se a investigar o estágio de gestão ambiental de unidades do setor varejista, principalmente, as de pequeno e médio porte.

Outro aspecto para pesquisas futuras refere-se à análise do posicionamento de faturamento dos supermercados, de modo a identificar eventual reciprocidade entre a inserção da variável ambiental e melhores resultados financeiros. Empresas que adotam a RSC devem alinhar sua gestão econômica à gestão social e ambiental, assim eventuais vantagens competitivas relacionadas à atração e fidelização de clientes também podem ser objeto de pesquisa quanto à implantação de um SGA interligado à estratégia e valores da organização.

\begin{abstract}
The supermarket retail industry is the leading of consumer products selling in Brazil and one of the main sectors of national economy. The supermarket retail supply chain causes environmental impacts related to depletion of natural resources and waste generation. The major supermarket chains have been performing actions related to the environment protection. For the discussion of the integration of the environmental dimension in the conventional supermarket operations in Brazil, this article aims at discussing the environmental management practices of the retail supermarket disclosed by six major supermarket chains: three international and three national. The environmental management system practices of these enterprises were analyzed according to the established in ISO 14001. The results show that the environmental aspects of the typical sections of conventional supermarkets, identified based on primary data, are considered into environmental practices adopted by the companies studied. As the main steps of the environmental management system only environmental policy and planning stages are largely disclosed in the official network sites. The absence of data from implantation and checking stages does not allow evaluating the
\end{abstract}


effectiveness of environmental management on the environmental aspects of retail supermarket sector.

Key words: retail; supermarket; environmental management system; environmental impact.

\section{Referências}

AMADEU JUNIOR, A.; GELMAN, J. J.; MACEDO, L. C. A mobilização do setor varejista para a responsabilidade social: do assistencialismo ao alinhamento estratégico. In: GELMAN, J. J.; PARENTE, J. (Org.). Varejo socialmente responsável. Porto Alegre: Bookman, 2008. Cap. 1, p. 15-32.

ARAUJO, G. J. F.; CARVALHO, C. M. As políticas sustentáveis aplicadas às redes varejistas. Revista Administração em Diálogo, v. 13, n. 1, p. 47-63, jan./abr. 2011.

ASSOCIAÇÃO BRASILEIRA DE NORMAS TÉCNICAS. NBR ISO 14001: Sistemas de gestão ambiental Requisitos com orientações de uso. Rio de Janeiro: ABNT, 2004. 27 p.

ASSOCIAÇÃO BRASILEIRA DE SUPERMERCADOS. Guia da loja verde. São Paulo: APAS, 2011. 94 p.

ASSOCIAÇÃO BRASILEIRA DE SUPERMERCADOS. Guia prático APAS: supermercado sustentável. São Paulo: APAS, 2008. $74 \mathrm{p}$.

ASSOCIAÇÃO BRASILEIRA DE SUPERMERCADOS. Panorama Superhiper 2011. São Paulo: Abras, 2010.

ASSOCIAÇÃO BRASILEIRA DE SUPERMERCADOS. Superhiper - Ranking Abras 2013: a análise do autosserviço. São Paulo: Abras, 2014.

BARBIERI, J. C. Gestão ambiental empresarial: conceitos, modelos e instrumentos. São Paulo: Saraiva, 2004. 328 p.

BARROS, R. A. et al. Práticas de sustentabilidade empresarial no APL calçadista de Campina Grande-PB: um estudo de caso. Revista Gestão Industrial, v. 6, n. 1, p. 157-177, 2010.

BRAGA JUNIOR, S. S. Gestão ambiental no varejo: um estudo das práticas de logística reversa em supermercados de médio porte. 2007. Dissertação (Mestrado)- Faculdade de Economia, Administração e Contabilidade de Ribeirão Preto, Universidade de São Paulo, Ribeirão Preto, 2007.

CAMPOS, L. M. S. Environmental management systems (ems) for small companies: a study in southern Brazil. Journal of Cleaner Production, v. 32, p. 141-148, 2012. crossref

CARREFOUR. Consulta geral a homepage oficial Brasil. Disponível em: <http://www.carrefour.com.br/>. Acesso em: 06 set. 2011a.

CARREFOUR. Consulta geral a homepage oficial do grupo no Brasil. Disponível em: <http://www.grupocarrefour.com.br/>. Acesso em: 08 set. 2011 b.

CARREFOUR. Consulta geral a homepage oficial mundial. Disponível em: <http://www.carrefour.com/>. Acesso em: 09 maio 2012.

CARREFOUR. Consulta geral ao site c-laterre.fr. (site do desenvolvimento sustentável do Carrefour). Disponível em: <http://www.c-

laterre.fr/?svc_mode=E \&g=233033193305\&svc_campaign=rubrique\&svc_partner=ClaTerre\&svc_position=CRF\&estat _url=http\%3A\%2F\%2Fwww.c-laterre.fr\%2F>. Acesso em: 06 set. 2011c.

CARREFOUR. Rapport expert 2010: Le développement durable chez Carrefour. 162p. Disponível em:

<http://www.carrefour.com/docroot/groupe/C4com/Commerce\%20responsable/Publications/RDD_Expert_2010_compl et_250711_DEF.pdf >. Acesso em: 06 set. 2011d.

CARREFOUR. Relatório de desenvolvimento sustentável 2009. 59p. Disponível em:

<http://www.grupocarrefour.com.br/wp-content/uploads/2010/02/27646_RDS_2009.pdf〉. Acesso em: 06 ago. 2010. 
CONSUMERS INTERNATIONAL. Les supermarchés europeéns aux banc d'essai: sont-ils à La hauteur de leurs responsabilités em matière de conditions de travail dans Le monde em développements? 2010b. 60p. Disponível em: <http://www.consumersinternational.org/media/394318/checkedout-fran\%C3\%A7ais-02.pdf >. Acesso em: 27 nov. 2010.

COOP AMBIENTE. Consulta geral a homepage. Disponível em: <http://www.coopambiente.it/>. Acesso em: 21 fev. 2012.

COOP ITÁLIA. 2010 Settimo rapporto sociale nazionale: della cooperazione di consumatori [Coop]. Casalecchio di Reno: Euro Coop Itália, 2011. 125p. Disponível em: <http://www.ecoop.it/portalWeb/stat/docPortale/doc00000057190/true/rapporto-sociale-nazionale-.dhtml>. Acesso em: 21 fev. 2012.

COOP ITALIA. L’impegno di Coop per l'ambiente. 2007. 23p. Disponível em: <http://www.ecoop.it/CoopRepository/COOP/CoopItalia/file/fil00000039351.pdf>. Acesso em: 14 nov. 2010.

CRUZ, L. B.; PEDROZO, E.; MARTINET, A. Estratégias de desenvolvimento sustentável em grupos multinacionais: o estudo de dois casos franceses no setor do varejo. Revista de Gestão Social e Ambiental, São Paulo, v. 1, n. 3, p. 5878. set./ dez. 2007.

DELAI, I.; TAKAHASHI, S. Corporate sustainability in emerging markets: insights from the practices reported by the Brazilian retailers. Journal of Cleaner Production, Amsterdam, v. 47, p. 211-221, 2013. crossref

DEMAJOROVIC, J. Ecoeficiência em serviços: diminuindo impactos e aprimorando benefícios ambientais. In: VILELA JÚNIOR, A.; DEMAJOROVIC, J. (Org.). Modelos e ferramentas de gestão ambiental: desafio e perspectivas para as organizações. São Paulo: Editora SENAC, 2006. p. 169-198.

E-COOP. Consulta geral a homepage oficial. Disponível em: 〈http://www.e-coop.it/portalWeb/portale/index.jsp>. Acesso em: 21 fev. 2012.

EPELBAUM, M. Sistemas de gestão ambiental. In: VILELA JÚNIOR, A.; DEMAJOROVIC, J. (Org.) Modelos e ferramentas de gestão ambiental: desafio e perspectivas para as organizações. São Paulo: Editora SENAC, 2006. p. 115-148.

EROL, I. et al. Sustainability in the Turkish Retailing Industry. Sustainable Development, Toronto, v. 17, p. 49-67, 2009. cross ref

FEDERAÇÃO DAS INDÚSTRIAS DO ESTADO DE SÃO PAULO. Melhore a competitividade com o sistema de gestão ambiental - SGA. São Paulo: FIESP, 2007. 83 p.

FERENHOF, H. A. et al. Environmental management systems in small and medium-sized enterprises: an analysis and systematic review. Journal of Cleaner Production, v. 74, p. 44-53, July, 2014. crossref

FERES, Y. N. Indicadores para avaliação de desempenho ambiental aplicáveis ao varejo supermercadista brasileiro. 2009. 197 f. Dissertação (Mestrado Profissional - Tecnologia Ambiental) - Instituto de Pesquisas Tecnológicas de Estado de São Paulo, São Paulo.

FUNDAÇÃO GETÚLIO VARGAS. Escola de Administração de Empresas de São Paulo. Instituto Ethos. Indicadores de responsabilidade social nas empresas varejistas. São Paulo: FGV, 2005. 72 p.

GALLEZ, C.; MORRONCINI, A. Le manager et l'environnement: outils d'aide à la decision stratégique et opérationnelle. Lausanne: Presses polytechniques et universitaires romandes, 2003. 248 p.

GONZÁLEZ-BENITO, J.; LANNELONGUE, G.; QUEIRUGA, D.. Stakeholders and environmental management systems: a synergistic influence on environmental imbalance. Journal of Cleaner Production, v. 19, n. 14, p. 16221630, 2011. crossref

GRUPO PÃO DE AÇÚCAR. Consulta geral a homepage oficial. Disponível em: <http://www.grupopaodeacucar.com.br/home.htm>. Acesso em: 20 fev. 2012 b.

GRUPO PÃO DE AÇÚCAR. Consulta geral a homepage relação com investidores. Disponível em:

<http://www.gpari.com.br/grupopaodeacucar/web/default_pt.asp?idioma=0\&conta=28 >. Acesso em: 20 fev. $2012 \mathrm{a}$. 
GRUPO PÃO DE AÇÚCAR. Relatório anual e de Sustentabilidade 2010. São Paulo: GPA, 2011. 127p. Disponível em: <http://www.gpari.com.br/grupopaodeacucar/web/conteudo_pt.asp?idioma=0\&conta=28\&tipo=29910>. Acesso em: 20 fev. 2012c.

HAMZA, K. M.; DALMARCO, D. A. Integração entre estratégia competitiva e práticas de responsabilidade social corporativa: um estudo exploratório nos cinco maiores supermercados brasileiros. Revista de Gestão Social e Ambiental - RGSA, São Paulo, v. 6, n. 3, p. 78-95, set./dez. 2013.

HERZOG, A. L. Parem de gastar tanto dinheiro. In: Guia Exame de Sustentabilidade. São Paulo: Editora Abril, 2008. Disponível em: <http://planetasustentavel.abril.com.br/noticia/desenvolvimento/conteudo_265708.shtml?func=2>. Acesso em: 28 ago. 2010.

INSTITUTO BRASILEIRO DE GEOGRAFIA E ESTATÍSTICA. Consulta geral a homepage oficial. Disponível em: <http://www.ibge.gov.br/home/estatistica/economia/contasnacionais/2009/tabelas_pdf/tab10.pdf>. Acesso em: 10 maio 2012.

INSTITUTO ETHOS. Consulta geral a homepage oficial. Disponível em: <http://www1.ethos.org.br/EthosWeb/Default.aspx>. Acesso em: 27 nov. 2010.

LLACH, J. et al. Joint impact of quality and environmental practices on firm performance in small service businesses: an empirical study of restaurants. Journal of Cleaner Production, v. 44, p. 96-104, 2013. crossref

MARQUES, F.; MENDONÇA, P. S. M.; JABBOUR, C. J. C. Social dimension of sustainability in retail: case studies of small and medium Brazilian supermarkets. Social Responsibility Journal, Bingley, v. 6, n. 2, p. 237-251, 2010.

MORROW, D.; RONDINELLI, D. Adopting corporate environmental management systems: motivations and results of ISO 14001 and EMAS Certification. European Management Journal, London, v. 20, n. 2, p. 159-171, 2002.

crossref

MOTTA, S. L. S.; ROSSI, G. B. A influência do fator ecológico na decisão de compra de bens de conveniência.

Revista de Administração do Mackenzie, São Paulo, v. 2, n. 2, p. 109-130, 2001.

OLIVEIRA, R. L.; MACHADO, A. G. Gestão ambiental empresarial: estudo de casos em empresas líderes dos setores supermercadistas e de refrigerantes. Revista de Gestão Social e Ambiental, São Paulo, v. 4, n. 2, p. 21-39, maio/ago. 2010.

PARENTE, J. et al. Fórum de Varejo e Consumo Sustentável: experiências, debates e desafios. São Paulo: FGV, 2009. Disponível em: <http://www.varejosustentavel.com.br>. Acesso em: 22 abr. 2011.

PARENTE, J. Varejo no Brasil: gestão e estratégia. São Paulo: Atlas, 2007. 388 p.

RAFUL, N. F.; JUCHEM, D. M.; CAVALHEIRO, M. E. Gestão ambiental como diferencial competitivo empresarial. Revista Gestão Industrial, v. 6, n. 2, 2010.

REINARTZ, W. et al. Retailing innovations in a globalizing retail market environment. Journal of Retailing, v. 87, p. S53-S66, 2011. crossref

SANCHÉZ, L. E. Avaliação de impacto ambiental: conceitos e métodos. In: Avaliação de impacto ambiental: conceitos e métodos. 2. ed. São Paulo: Oficina de Textos, 2014.

SEIFFERT, M. E. B. Environmental impact evaluation using a cooperative model for implementing ems (iso 14001) in small and medium-sized enterprises. Journal of Cleaner Production, v. 16, n. 14, p. 1447-1461, Sept. 2008. crossref

SOARES, D. C.; PIMENTA, H. C. D. Auditoria de sistema de gestão ambiental: aplicação em uma indústria alimentícia em Natal/RN. Revista de Gestão Social e Ambiental, São Paulo, v. 5, n. 1, p. 66-84, jan./abr. 2011.

STYLES, D.; SCHOENBERGER, H.; GALVEZ-MARTOS, J.-L. Environmental improvement of product supply chains: Proposed best practice techniques, quantitative indicators and benchmarks of excellence for retailers. Journal of Environmental Management, v. 110, p. 135-150, 2012. crossref 
SUAMIR, I. N.; TASSOU, S. A.; MARRIOT, D. Integration of CO2 refrigeration and trigeneration systems for energy and GHT emission saving in supermarkets. International Journal of Refrigeration, v. 35, n. 2, p. 407-417, 2012.

crossref

TESCO PLC. Corporate Responsability Report 2011. Hampshire: Scott Wilson, 2011. Disponível em: <http://www.tescoplc.com/media/60113/tesco_cr_report_2011_final.pdf>. Acesso em: 17 mar. 2012.

TESCO. Consulta geral a homepage oficial. Disponível em: <http://www.tesco.com/>. Acesso em: 17 mar. 2012.

TESCO. Environment sustainability statement: Tesco environment store, Greater Eston. Hampshire: Scott Wilson, 2010. 41 p.

THOMPSON, B. Green Retail: Retailer Strategies for Surviving the Sustainability. Storm. Journal of Retail and Leisure Propert, Germantown, v. 6, n. 4, p. 181-186. 2007.

WALKER, D. Sustainability: environment management, transparency and competitive advantage. Journal of Retail and Leisure Property, Germantown, v.7, p. 119-130, 2008. Disponível em: <http://www.palgrave-

journals.com/rlp/journal/v7/n2/full/rlp20084a.html>. Acesso em: 13 maio 2012.

WALMART BRASIL. Consulta geral a homepage oficial. Disponível em: <http://www.walmartbrasil.com.br/>. Acesso em: 05 ago. 2010.

WALMART BRASIL. Relatório de sustentabilidade 2008: exercício 2007. Barueri: Ipsis Gráfica e Editora, 2008. $107 \mathrm{p}$.

WALMART BRASIL. Relatório de sustentabilidade 2011: exercício 2010. Barueri: Editora Contadino, 2011.77 p.

WALMART CORPORATIVO. Consulta geral a homepage oficial. Disponível em: <http://www.walmartstores.com>. Acesso em: 01 out. 2011.

WALMART INTERNACIONAL. Consulta geral a homepage oficial. Disponível em: <http://www.walmart.com>. Acesso em: 01 out. 2011.

WALMART SUSTENTABILIDADE. Consulta geral a homepage oficial. Disponível em: <http://www.walmartsustentabilidade.com.br>. Acesso em: 01 nov. 2011.

WHOLE FOODS MARKET. 2010 annual report. Austin, Texas: WFM, 2010. 68 p. Disponível em:

<http://www.wholefoodsmarket.com/company/pdfs/ar10.pdf>. Acesso em: 21 jun. $2011 \mathrm{~b}$.

WHOLE FOODS MARKET. Consulta geral a homepage oficial. Disponível em:

<http://www.wholefoodsmarket.com/>. Acesso em: 21 jun. 2011.

WIESE, A. et al. Sustainability in retailing - a summative content analysis. International Journal of Retail \& Distribution Management, Bradford, v. 40, n. 4, p. 318-335, 2012. crossref

YIN, R. K. Estudo de caso: planejamento e métodos. Porto Alegre: Bookman, 2005.

\section{Dados dos autores:}

Nome completo: Alain Jacques Camille Winandy

Filiação Institucional: Associação Brasileira de Supermercados - ABRAS

Função ou cargo ocupado: Diretor Abras São Paulo

Endereço completo: Av. Diógenes Ribeiro de Lima, 2872. Alto da Lapa. São Paulo. SP. CEP.: 05083-901.

Telefone para contato: 1138384529

e-mail: alainwinandy@gmail.com 
Nome completo: Amarilis Lucia Casteli Figueiredo Gallardo

Filiação Institucional: Universidade de São Paulo e Universidade Nove de Julho

Função ou cargo ocupado: Professora doutora do Departamento de Engenharia Hidráulica e Ambiental da Escola Politécnica da USP e da Pós-graduação em Gestão Ambiental e Sustentabilidade da Uninove.

Endereço completo para correspondência: Av. Dr. Cândido Motta Filho, 183, apt. 72/D. Vila São Francisco, São Paulo/SP. CEP 05351-000. Brasil.

Telefone para contato: 1130915592

e-mail: amarilislcfgallardo@gmail.com

'Informação obtida por meio de consulta via e-mail, com Sr. Victor Barros, da Comunicação e Mobilização do Instituto Ethos.

Submetido em: 04/09/2014

Aceito em: 17/12/2014 